\title{
Carcass and meat quality characteristics of Beni-Guil autochthonous ovine breed: effect of live weight at slaughter
}

\author{
Kamal Belhaj ${ }^{1,2^{*}}$, Farid Mansouri ${ }^{2}$, Youssef Rbah $^{2}$, Aymane Allay $^{2}$, reda Melhaoui ${ }^{1}$, Aziz Tikent $^{2,3}$, Yassine Taaifi ${ }^{2,3}$, \\ Abdessamad Benmoumen ${ }^{1}$, Mohamed Boukharta ${ }^{4}$, Marianne Sindic ${ }^{5}$, Hana Serghini-Caid ${ }^{2}$, Ahmed Elamrani ${ }^{2}$ \\ ${ }^{1}$ Laboratoire de Management de l'Agriculture Durable, EST Sidi Bennour, Université Chouaib Doukkali, El Jadida \\ ${ }^{2}$ Laboratoire d'Amélioration de la Production Agricole, Biotechnologie et Environnement (LAPABE), F Université \\ Mohamed Ier, Oujda; Maroc. 717, 60000 Oujda, Maroc. \\ ${ }^{3}$ Service Vétérinaire, Office National de Sécurité Sanitaire des produits Alimentaires, Oujda, Maroc. \\ ${ }^{4}$ Institut Supérieur Industriel agronomique, Huy, Belgique. \\ ${ }^{5}$ Laboratoire Qualité et Sécurité des Produits Alimentaires, Gembloux Agro-Bio Tech, Université de Liège ; Belgique.
}

\begin{abstract}
Ninety female lambs of the Beni-Guil sheep breed were used to study the effect of slaughter live weight (SLW) on carcass characteristics and meat quality. The animals were raised in Morocco's eastern area under a pastoral-transhumant system. The lambs were slaughtered at three weight classes (SLW1 $=20-25 \mathrm{~kg}$, SLW2 $=26-30 \mathrm{~kg}$, SLW3 $=31-35 \mathrm{~kg}$ ). Ultimate $\mathrm{pH}$ value $(\mathrm{pHu}$ ), fat and meat color, zoometric measurement, conformation score, fatness state, and fat consistency were evaluated $24 \mathrm{~h}$ post-slaughter. The carcass measures and compactness indexes increase with higher SLW $(p<0.001)$. However, the dressing percentage and shrinkage were not affected. The longissimus lumborum muscle was used for meat quality determination. The $\mathrm{pHu}$ was not affected $(p>0.05)$ by SLW effect. With respect to meat color, the lightness $\left(\mathrm{L}^{*}\right)$ decreased with increasing SLW, while the redness increased $(p<0.05)$. The female lambs with a carcass weight of $20-25 \mathrm{~kg}$ have a higher $L^{*}$ value (41.89), and lambs with a carcass weight between 31 and $35 \mathrm{~kg}$ have a higher redness value (21.73). In relation to the $c^{1}$ arcass fatness state and carcass conformation, the SLW had a significant effect $(p<0.001)$. The conformation and the fatness increase in the logical sequence of SLW.
\end{abstract}

\section{Introduction}

The total ruminant population in Morocco currently numbers about 29 million heads divided between cattle, sheep, goats and camels. The sheep sector ranks first with a workforce of around 20 million heads, contributing $30 \%$ to national meat production [1]. The Moroccan sheep population is composed by more than $95 \%$ of autochthon breeds [2]. The Beni-Guil, Sardi, Timahdite, D’man, Boujâad, Beni-Hsen, Black Siroua Mountain White, and Saghro are the main sheep breeds having major socio-economic concerns [3]. The sheep production is mainly based on pastoral-transhumant systems exploiting local breeds. To have sustainable use, create added value to products, and provide more opportunities for breeders, the Moroccan government focuses on developing local breeds in their cradles through the preservation of local breeds in their origin area, average daily gain improvement and product certifications. Since 2011, the Moroccan Institute for Standardization has granted the Beni-Guil sheep meat as a Protected geographical indication (PGI) the from eastern region of Morocco, (ministerial order $\mathrm{n}^{\circ} 1164$ 11 du joumada II1432 (5 may 2011)). This PGI breed is among the main local breeds exploited in Morocco with a workforce of around 2 million heads. This sheep breed is born, reared, and slaughtered in the eastern Moroccan region, fed a particular diet and reared under specific pastoral-transhumant system of this region. It is well suited to the harsh climate and poor pasture conditions, and is classified as a meat production breed. It is a breed characterized by fire brown head, ears, prothorax, and legs, without white spots, white fleece, and no horns in the female (Figure 1). The rams usually have coarse and long horns that are pale and spiral (Figure 2). The Beni-Guil sheep meat has a unique sensory and nutritional quality linked to this distinct environment and natural grazing system. The heavy lamb's meat is less tender with a strong flavour and high fat content [4]. The consumers in Moroccan rural areas prefer heavy carcasses from adult animals; while in urban areas, the meat from light animals

\footnotetext{
*Corresponding author: belhaj.kama190@gmail.com ; k.belhaj@ump.ac.m
} 
is favoured (generally meat of young animals). The Beni-Guil sheep meat label only takes into account the meat from animals with milk teeth, slaughtered at 120-180 days of age. However, the meat from adult animals also needs to be considered. Various factors affect the sheep meat quality, such as feed [5], live weight at slaughter [6], genotype [7], and sex [8]. There are no previous studies on carcass and meat quality characteristics of Beni-Guil sheep breed slaughtered at different weight. Hence, this study aims to determine the effect of live weight at slaughter $(20-25 \mathrm{~kg} ; 26-30 \mathrm{~kg} ; 31-35 \mathrm{~kg})$ on carcass and meat quality of Beni-Guil-PGI sheep, and therefore, to contribute to the characterization of this Moroccan label.

\section{Materials and methods}

\subsection{Animals}

Animals were reared under transhumant-local production systems in the pasture of eastern Morocco highlands. A total of 90 single-born female lambs reared extensively were slaughtered during spring 2018 at three slaughter weights classes; SLW 1: 20-25 kg, SLW 2: 26-30 kg, and SLW 3: $31-35 \mathrm{~kg}$ ( $\mathrm{n}=30$ for each group) for determining slaughter, carcass, and meat quality characteristics traits. The studied animals were weaned at the age of 3 months and were not shorn. The selected animals were weighed and slaughtered after a 12 -h fasting period with free access to water. Female lambs were slaughtered in their areas of origin in a slaughterhouse. Further details about rearing, diet composition and slaughter conditions are described by Belhaj, Mansouri [9]. The study period was from February to July 2018. The longissimus lumborum samples were taken 24 hours post-mortem with the assistance of a slaughterhouse veterinarian for color measurement.

The study was conducted on two slaughterhouses located in the eastern region of Morocco that of Oujda and Jerrada. The climate of this area is semi-arid. The annual rainfall varies between 100 and $250 \mathrm{~mm} / \mathrm{year}$ and the average annual temperature is around $19{ }^{\circ} \mathrm{C}$ with lows that can reach $-4{ }^{\circ} \mathrm{C}$ in winter and average maximums of around $42.5^{\circ} \mathrm{C}$ in summer season [10].

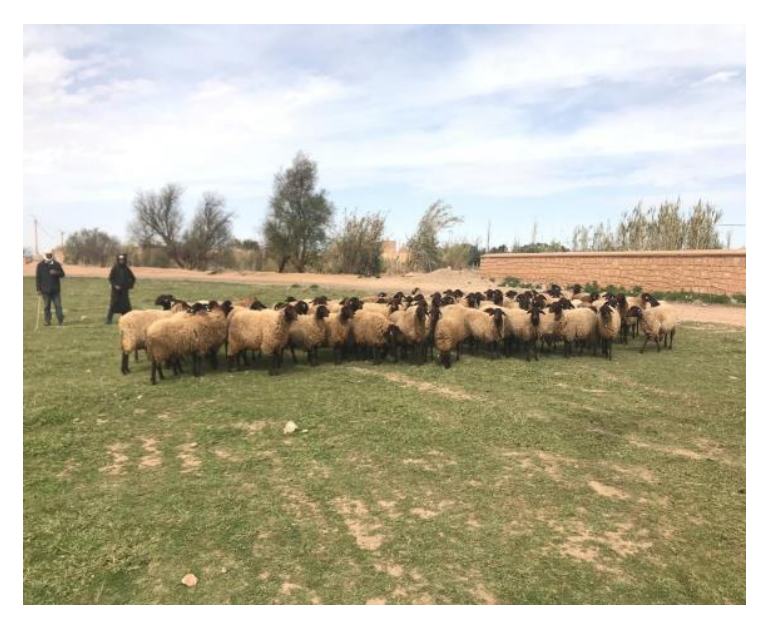

Fig 1. Female lambs of Beni-Guil sheep breed

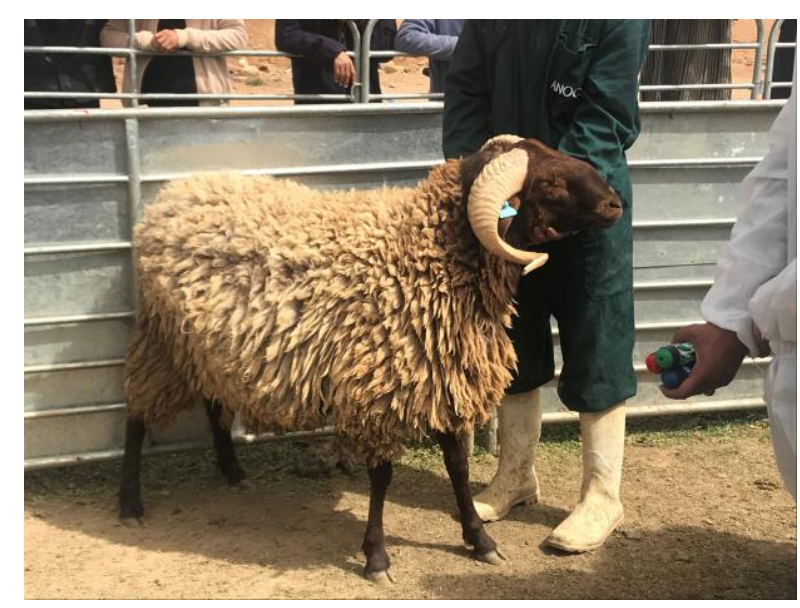

Fig 2. Male lambs from the super category of BeniGuil sheep breed

\subsection{Carcass and meat measurements}

The details of the methods used to assess the Beni-Guil sheep breed's carcass and meat quality characteristics carcass and meat quality characteristics of Beni-Guil sheep breed are described by Belhaj, Mansouri [11].

\subsection{Statistical analysis}

Statistical analyses were conducted using Statistical Package for the Social Sciences (IBM SPSS. 20). The normal distribution was verified according to the Shapiro Wilk test for quantitative variables. A two-way analysis of variance (ANOVA) was carried out for the live weight at slaughter. Tukey's post-hoc test was used for means comparison. The difference was considered significant at $p<0.05$. Principal component analysis (PCA) was performed on the data set to differentiate the samples according to their breed and age at slaughter and to obtain more information on the variables that mainly influence the carcass of our samples. 


\section{Results and discussion}

\subsection{Carcass measurements}

The obtained values for the effect of slaughter live weight on carcass characteristics of Beni-Guil female lambs are given in table 1 . The weight measurement particularly the carcass weight and the yield are important production and slaughter criteria for breeders, butchers, and retailers. These slaughter parameters are affected by several factors such as alimentary tract size and fill, slaughtering processes, fleece or skin mass, fatness state, and sexual organs. The mean hot and cold carcass weight ranged between 10.72-15.96 kg and 10.55-15.67 kg respectively for hot and cold carcass weight. These slaughter parameters varied according to the slaughter live weight: carcasses of SW-class 3 were heavy than other groups. However, the slaughter data highlighted the no significant effect of live weight on economic and commercial yield. The animal's age significantly influenced $(p<0.001)$ the yield at slaughter (data not shown). Authors reported similar results for other sheep breeds [12-14]. Contrary to this finding, Liu, Guo [6] obtained a significant effect of SLW on carcass yield for Oula lambs slaughtered at five live weight. These contradictory results could be attributed to the difference in SLW, in particular the difference between studied weight classes (Liu, Guo [6] : 25-45 kg present study : 20-35 kg), animals' age at slaughter, and sex. The recorded carcass yield values are higher than those reported by Blasco, Campo [15] for Texel breed and by Yaranoğlu and Özbeyaz [16] for three Turkish breeds. However, these values are lower than those reported by Santos, Cabo [14], and Santos, Silva [13] for Churra Galega Mirandesa breed (50-57 kg) and Churra da Terra Quente breed (48-50 kg). Firstly, this difference could be explained by alimentary tract size and fill, because the animals studied by Santos, Cabo [14], and Santos, Silva [13] are not functional as ruminants, and therefore have a lower digestive tract content and size (lower weight of offal). Secondly the fleece size because the female lambs have a fleece with long hair in the present study.

Table 1. Effect of live weight at slaughter on carcass traits of Beni-Guil sheep breed from eastern Morocco (means \pm SD).

\begin{tabular}{ccccc}
\hline Parameters & \multicolumn{3}{c}{ Live weight classes } & \multirow{2}{*}{ P value } \\
\cline { 2 - 4 } & $\mathbf{2 0 - 2 5 ~ k g}$ & $\mathbf{2 6 - 3 0 ~ k g}$ & $\mathbf{3 1 - 3 5 ~ k g}$ & \\
\hline Weight measurements & & & & \\
Hot Carcass Weight $(\mathrm{Kg})$ & $10.72 \pm 0.98^{\mathrm{a}}$ & $14.07 \pm 0.78^{\mathrm{b}}$ & $15.96 \pm 0.89^{\mathrm{b}}$ & $<0.001$ \\
Cold Carcass Weight $(\mathrm{Kg})$ & $10.51 \pm 0.98^{\mathrm{a}}$ & $13.80 \pm 0.78^{\mathrm{b}}$ & $15.67 \pm 0.87^{\mathrm{c}}$ & $<0.001$ \\
Economic yield (\%) & $48.08 \pm 1.47^{\mathrm{a}}$ & $48.16 \pm 2.48^{\mathrm{a}}$ & $47.37 \pm 1.49^{\mathrm{a}}$ & $\mathrm{NS}$ \\
Commercial yield (\%) & $47.11 \pm 1.47^{\mathrm{a}}$ & $47.24 \pm 2.45^{\mathrm{a}}$ & $46.49 \pm 1.46^{\mathrm{a}}$ & $\mathrm{NS}$ \\
Shrinkage loss (\%) & $2.02 \pm 0.40$ & $1.90 \pm 0.42$ & $1.85 \pm 0.26$ & $\mathrm{NS}$ \\
linear measurements & & & & \\
G (cm) & $14.17 \pm 3.59^{\mathrm{a}}$ & $16.60 \pm 0.52^{\mathrm{b}}$ & $16.81 \pm 0.68^{\mathrm{b}}$ & $<0.01$ \\
K (cm) & $58.05 \pm 1.08^{\mathrm{a}}$ & $61.43 \pm 0.99^{\mathrm{b}}$ & $61.22 \pm 0.35^{\mathrm{b}}$ & $<0.001$ \\
F (cm) & $27.68 \pm 0.90^{\mathrm{a}}$ & $31.35 \pm 1.60^{\mathrm{b}}$ & $31.36 \pm 1.09^{\mathrm{b}}$ & $<0.001$ \\
LCI = G/F & $0.54 \pm 0.04$ & $0.53 \pm 0.03$ & $0.54 \pm 0.03$ & $\mathrm{NS}$ \\
CCI1 = G/K & $0.26 \pm 0.02^{\mathrm{a}}$ & $0.27 \pm 0.01^{\mathrm{b}}$ & $0.27 \pm 0.01^{\mathrm{b}}$ & $<0.05$ \\
CCI2=CCW/K $(\mathrm{g} / \mathrm{cm})$ & $181.02 \pm 16.70^{\mathrm{a}}$ & $224.76 \pm 12.4^{\mathrm{b}}$ & $255.95 \pm 14.80^{\mathrm{c}}$ & $<0.001$ \\
Subjective characteristics & & & & \\
EUROP-Conformation & $2.00 \pm 0.00^{\mathrm{a}}$ & $2.33 \pm 0.49^{\mathrm{a}}$ & $2.85 \pm 0.36^{\mathrm{c}}$ & $<0.001$ \\
EUROP-Fatness & $2.95 \pm 0.22^{\mathrm{a}}$ & $3.16 \pm 0.38^{\mathrm{a}}$ & $3.58 \pm 0.51^{\mathrm{b}}$ & $<0.001$ \\
Fat color & $1.00 \pm 0.00$ & $1.00 \pm 0.00$ & $1.00 \pm 0.00$ & $\mathrm{NS}$ \\
Fat firmness & $1.00 \pm 0.00$ & $1.00 \pm 0.00$ & $1.00 \pm 0.00$ & $\mathrm{NS}$ \\
\hline
\end{tabular}

Values with different superscript letters are significantly $(p<0.05)$ different within row.

G: Basin width; K: Carcass length; $\mathbf{F}$ : Leg length; NS: not significant.

LCI: Leg compactness index; CCI1: Carcass compactness index1; CCI2: Carcass compactness index2;

Conformation $(1=$ Poor to $5=$ Excellent $)$; Fatness state $(1=$ Very low to Very high); Fat color scale $(1=$ very white to 4 = strongly colored); Fat firmness scale ( 1 = hard to $4=$ very soft and oily).

All-the linear measurements were significantly affected by live weight at slaughter (Table 1). The results showed that the carcass linear measures and carcass compactness indices (CCI 1 and CCI 2) increase gradually in the logical sequence of their SLW $(p<0.05)$, showing higher values for animals of SLW-class $3(p<0.001)$. As slaughter weight increases, the carcass compactness increases, as shown by Liu, Guo [6], and Santos, Cabo [14] 
who compared carcass and meat quality traits of Oula and Churra Galega Mirandesa sheep breed slaughtered at different weights. The obtained carcass compactness values based on carcass weight are higher than those found in the carcass of the Churra Galega Mirandesa breed $(23.1 \mathrm{~g} / \mathrm{cm})$ slaughtered at two different slaughter weights [14]. Moreover, these carcass indices are comparable to those reported by Blasco, Campo [15] for the carcass of Texel sheep breed $(220-230 \mathrm{~g} / \mathrm{cm})$ in the case of weight-class 2 and $3(224-250 \mathrm{~g} / \mathrm{cm})$.

The meat market wants well-muscled carcasses with a high percentage of lean meat and a particular degree of fatness, to minimise weight loss during cold storage [12]. As shown in Table 1, carcass of SLW 1 group expelled more water than other groups, showing higher shrinkage loss value, but this difference was not significant. This water loss was correlated negatively with fatness state, since the fat layer represents an obstacle that prevents water loss during storage. A Similar correlation was reported by D'Alessandro, Maiorano [17] in Kivircik's sheep breed meat. The estimated shrinkage loss values are lower than those reported by Ekiz, Demirel [18], Carrasco, Ripoll [19], and D'Alessandro, Maiorano [17] for Kivircik (2.38-3.36\%), Chura (2.3-2.9\%) and Leccese (2.42-3.32\%) sheep breed, respectively. Concerning the carcass subjective quality, the results showed a significant effect of SLW on conformation and fatness state $(p<0.001)$. According to the community scale for classification of ovine carcasses (EUROP), all assessed carcasses were classified within fair $(\mathrm{O})$ and good $(\mathrm{R})$ score. As expected, the SLW 3 animal carcasses showed a higher conformation and fatness score. In line with previous studies [20, 21], increased slaughter weight increased the carcass conformity and fatness state. This could be explained in part by the tissue development at young age. The conformation of exanimated carcasses was comparable to that reported by Carrasco, Ripoll [19] for Churra Tensina lambs and by Blasco, Campo [15] for Texel breed and its crossbreeding (Texel $\times$ Segureña). In respect to fatness state, the obtained scores are slightly higher than those observed by Mazzone, Giammarco [22] in Apenine lamb carcasses (2.18-2.26) and are comparable to those estimated by Blasco, Campo [15] for Texel breed (2.25-3.45). Regarding the carcass fat and consistency, no significant difference was observed. All the assessed carcasses have a white and hard carcass fat. A similar result was reported by Carrasco, Ripoll [19] for Chura sheep breed.

\subsection{Carcass colour}

The colour is the principal quality for meat before purchase. It is the meat commercial quality. In term of consumer preference, the muscle colour must be bright red, indicates meat freshness. The results of colour coordinates lightness $\left(\mathrm{L}^{*}\right)$, redness index $\left(\mathrm{a}^{*}\right)$, yellowness index $\left(\mathrm{b}^{*}\right)$, Chroma $\left(\mathrm{C}^{*}\right)$, and hue angle $\left(\mathrm{H}^{*}\right)$ are presented in table 2. All obtained $L^{*}(41.19-41.89)$ values are in the bright red meat colour range $[6,23]$. The $L^{*}$ values decrease with increasing SLW, while the $\mathrm{a}^{*}$ increase $(p<0.05)$. These findings are in agreement with those reported by Beriain, Bas [24], Santos, Cabo [14] and Budimir, Trombetta [25] for other sheep breeds. This result can be attributed to difference in slaughter age, in particular the myoglobin content. This muscle pigment is linked with meat redness (higher $\mathrm{a}^{*}$ and lower $\mathrm{L}^{*}$ ). The studied carcasses were darker in comparison with several lambs' carcasses $[6,14,20,25]$. This difference could be ascribed to the intensive physical exercise of studied animals, reared under the typical traditional-transhumant production system of eastern Morocco (long-distance travel by animals to graze).

Table 2. Effect of live weight at slaughter on ultimate $\mathrm{pH}$ and meat color of Beni-Guil sheep breed from eastern Morocco (means $\pm \mathrm{SD}$ ).

\begin{tabular}{lcccc}
\hline Parameters & $\mathbf{2 0 - 2 5} \mathbf{~ k g}$ & $\mathbf{2 6 - 3 0 ~ k g}$ & $\mathbf{3 1 - 3 5} \mathbf{~ k g}$ & P value \\
\hline pH ultimate & $5.89 \pm 0.08$ & $5.77 \pm 0.09$ & $5.71 \pm 0.07$ & NS \\
$\mathrm{L}^{*}$ (lightness) & $41.89 \pm 0.2^{\mathrm{b}}$ & $41.59 \pm 0.42^{\mathrm{ab}}$ & $41.19 \pm 0.64^{\mathrm{a}}$ & $<0.05$ \\
$\mathrm{a}^{*}$ (redness) & $20.95 \pm 0.93^{\mathrm{a}}$ & $21.22 \pm 0.59^{\mathrm{ab}}$ & $21.73 \pm 1.04^{\mathrm{b}}$ & $<0.05$ \\
$\mathrm{~b}^{*}$ (yellowness) & $7.74 \pm 0.61$ & $7.37 \pm 0.46$ & $7.57 \pm 0.93$ & $\mathrm{NS}$ \\
Chromaticity $^{\text {Hue angle }}{ }^{\circ}$ & $22.35 \pm 0.9$ & $22.47 \pm 0.53$ & $23.02 \pm 1.2$ & NS \\
a $^{*} \mathrm{~b}^{*}$ & $29.29 \pm 1.75$ & $19.19 \pm 1.57$ & $19.54 \pm 1.16$ & $\mathrm{NS}$ \\
\hline
\end{tabular}

Values with different superscript letters are significantly $(p<0.05)$ different within row.

Scales of $L^{*}, a^{*}, b^{*}$, chroma and Hue: $a^{*}$ and $b^{*}:-60$ to 60 ; $L^{*}: 0$ to 100 ; chromaticity: $0-60$; hue: $0-360^{\circ}$ NS: not significant

\subsection{Ultimate $\mathrm{pH}$}

The meat $\mathrm{pH}$ is a vital chemical parameter because it influences practically all qualities of meat. The effect of slaughter live weight on ultimate $\mathrm{pH}$ is listed in Tables 2 . The recorded values ranged from 5.71 to 5.89 , indicating the normal post-mortem $\mathrm{pH}$ evolution (animals slaughtered under stress-free conditions). According to Tukey's 
test, there is no significant difference in the obtained $\mathrm{pH}$ values between the studied groups. These results a agree with those reported by several authors, who don't find differences in meat $\mathrm{pHu}$ of lambs slaughtered at the different live weight. These values are within the normal $\mathrm{pH}$ range of commercial meat [26], and are comparable to those previously reported by several authors for sheep meat $[4,6,17]$. In the current study, the $\mathrm{pHu}$ value showed a decreasing trend with increasing slaughter weight, but these differences were not statistically significant ( $5.89 \mathrm{vs}$ 5.77 vs $5.71 ; p>0.05)$. This negative correlation could be explained by sensitivity to pre-slaughter manipulation. The heavy animals are more stressed at slaughter and consequently exhibit a lower ultimate $\mathrm{pH}$ [26]. In addition this correlation could be linked to the muscle glycogen reserve because the animal of SLW 3 is older than those of other weight classes and has received more cereals promoting propionic acid production, which is considered as a muscular glycogen precursor [27]. This correlation was also observed by numerous researchers in several lambs meat $[6,28]$.

\subsection{Chemometric analysis of the carcass and meat quality characteristics}

A principal component analysis (PCA) was carried out to identify and determine the correlations between the studied animals and measured parameters. This analysis was performed using 14 variables, including weight measurements, carcass measures, and carcass subjective characteristics. PCA results indicate that the first three principal component (PC) account for more than $80 \%$ of the total variation (Table 3). The first PC explained $52.62 \%$ and the second explained $19.63 \%$. The studied lambs' projections on the factorial map reveal discriminating between the studied carcasses, allowing for a simplified summary of the interpretations already indicated. Figure 3 represents the factorial plane defined by the first and second PCs. The results of PCA showed that the most important variables, which explained a large part of the total variance, were the weight and carcass measurement. Two separated groups can be observed according to PC 1. Animals with SLW of 20-25 kg are located on the left side of the factorial map and differentiated from other groups (SLW 1 and 2). These latter are correlated positively with the weight and carcass measurements indicating that these animals have a heavy carcass ( $\mathrm{HCW}, \mathrm{CCW}$ and $\mathrm{CCI} 2$ ) with greater carcass zoometric measurements (K, F, G, H and Th). These correlations between carcass measurements and slaughter live weight agree Cañeque, Pérez [29] who found that while carcass weight was increased, carcass weight, CCI and zoometric measurements improved. Regarding the second PC, the relationship between studied animals is not clear. The most important variables, which are regrouped into the PC 2, were the carcass yield and leg compactness.

The PCA exposed the slaughter live weight effect on the carcass and meat quality characteristics of Beni-GuilPGI sheep breed. Researchers reported similar discrimination for carcasses from animals slaughtered at different weight classes [29-31].

Table 3. Three main components explaining more than $80 \%$ of the total information on the carcass and meat quality traits of Beni-Guil sheep breeds.

\begin{tabular}{|c|c|c|c|c|c|c|c|}
\hline \multirow{2}{*}{ Variables } & \multicolumn{3}{|c|}{ Principal component } & \multirow{2}{*}{ Variables } & \multicolumn{3}{|c|}{ Principal component } \\
\hline & 1 & 2 & 3 & & 1 & 2 & 3 \\
\hline $\mathrm{HCW}$ & 0,967 & $-0,104$ & $-0,004$ & $\mathrm{~F}$ & 0,762 & $-0,333$ & 0,175 \\
\hline $\mathrm{CCW}$ & 0,966 & $-0,133$ & $-0,009$ & EUROP-Fatness & 0,631 & 0,073 & 0,180 \\
\hline CCI 2 & 0,957 & 0,008 & 0,032 & EUROP-Conformation & 0,383 & $-0,311$ & $-0,212$ \\
\hline $\mathrm{H}$ & 0,915 & $-0,070$ & 0,050 & EY & 0,160 & 0,853 & 0,460 \\
\hline Th & 0,878 & $-0,019$ & 0,087 & $\mathrm{CY}$ & 0,212 & 0,850 & 0,433 \\
\hline G & 0,862 & 0,084 & $-0,208$ & LCI & 0,229 & 0,790 & $-0,521$ \\
\hline $\mathrm{K}$ & 0,849 & $-0,283$ & 0,121 & CCI 1 & 0,511 & 0,583 & $-0,539$ \\
\hline
\end{tabular}

HCW: Hot carcass weight; CCW: Cold carcass weight; EY: Economic yield; CY: Commercial yield; SL: Shrinkage loss; G: Basin width; K: Carcass length; F: Leg length; LCI: Leg compactness index; CCI 1: Carcass compactness index 1; CCI 2: Carcass compactness index 2. 


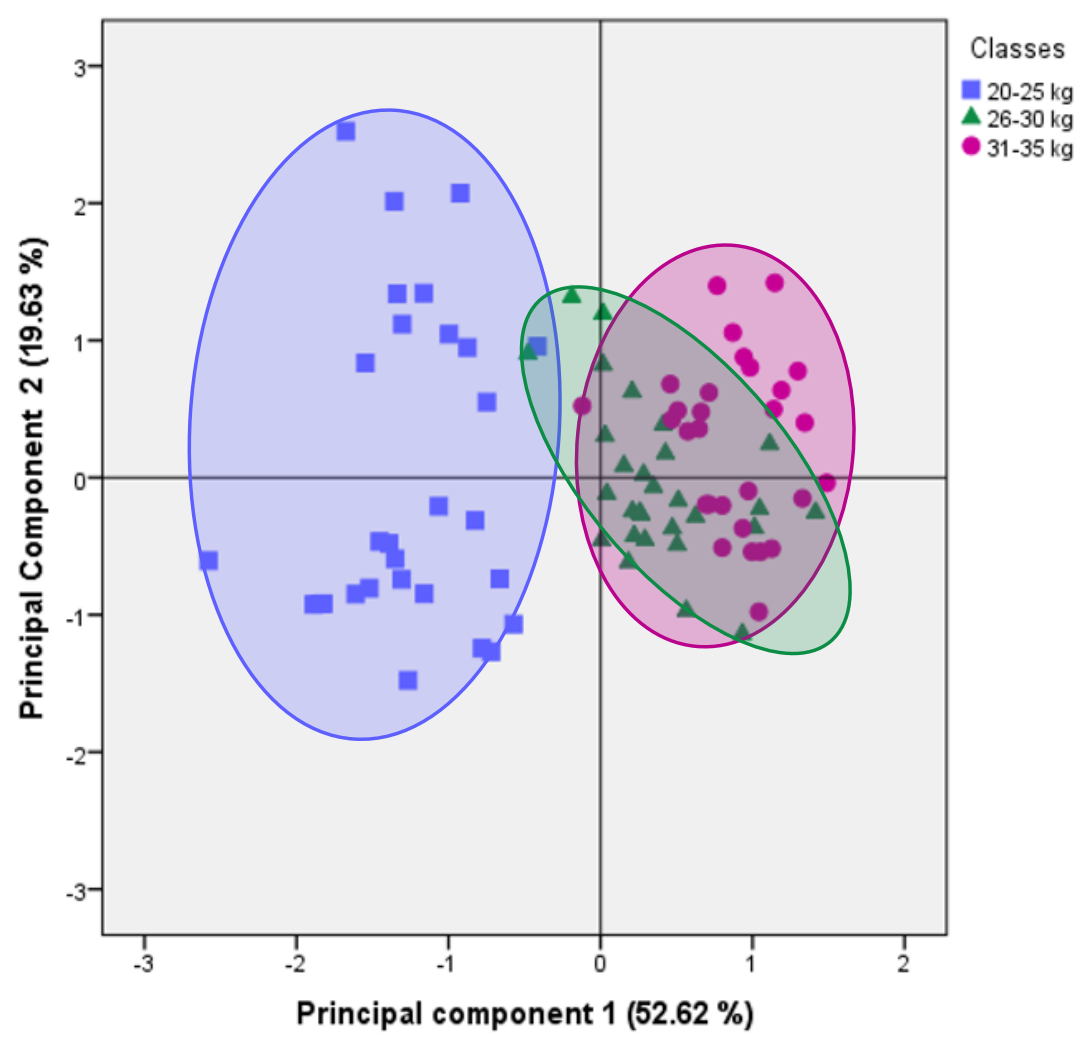

Fig. 3. Projection of the studied female lambs of Beni-Guil breed in the plane defined by the two principal components

\section{Conclusion}

The effect of live weight at slaughter on the carcass and meat quality traits has been studied. The results showed that this endogenous factor had a significant effect on the lamb's carcass and meat quality and should be considered in the PGI label to offer consumers a carcass with homogeneous traits from one purchase to another. This could increase consumer fidelity. In particular, the meat of female lambs slaughtered at 30-35 kg have a heavy carcass with better compactness, better conformation, and a high fatness state. On the other hand, those slaughtered at 20$25 \mathrm{~kg}$ have the optimal red coloration of the carcass (bright-red colour) with an average fatness state.

\section{Acknowledgments}

This paper is supported by Wallonie-Bruxelles International (WBI) as part of the project $1-6$. In addition, the authors are indebted to the ANOC "Association Nationale Ovine et Caprine" for its collaboration, particularly to Mr. A. Kacem, B. Belhaj, and A. Elmejdoubi.

\section{References}

1. HCP. Morocco in figures. 2019 [cited 13/06/2019; Available from: https://www.hcp.ma/downloads/Marocen-chiffres t13053.html.

2. A. Elbeltagy, Characterization and value addition to local breeds and their products in the Near East and North Africa, in Regional Workshop Rabat, Morocco. 2012, FAO: Rabat, Morocco. p. 19-21.

3. I. Boujenane, Small ruminant breeds of Morocco, in Characterization of small ruminant breeds in West Asia and North Africa, L. Iniguez, Editor. 2005, FAO: Rome. p. 5-54.

4. J.F. Tejeda, R.E. Peña, and A.I. Andrés, Meat science, 80, 1061-1067 (2008)

5. B. Ekiz, A. Yilmaz, H. Yalcintan, O. Kocak, and M. Ozcan, Large Animal Review, 26, 67-72 (2020)

6. J.-b. Liu, J. Guo, F. Wang, Y.-j. Yue, W.-1. Zhang, R.-1. Feng, T.-t. Guo, B.-h. Yang, and X.-p. Sun, Small Ruminant Research, 123, 251-259 (2015) 
7. A. Sabbioni, V. Beretti, E.M. Zambini, and P. Superchi, Italian Journal of Animal Science, 15, 2-9 (2016)

8. E. Miguel, B. Blázquez, and F. Ruiz de Huidobro, Liveweight and Sex Effects on Instrumental Meat Quality of Rubia de El Molar Autochthonous Ovine Breed. Animals 2021, 11, 1323. 2021, s Note: MDPI stays neu-tral with regard to jurisdictional claims in ....

9. K. Belhaj, F. Mansouri, M. Sindic, M.-L. Fauconnier, M. Boukharta, H. Serghini Caid, and A. Elamrani, Journal of Food Quality, 2021, (2021)

10. A. Bechchari, A. El Aich, H. Mahyou, B. Baghdad, and M. Bendaou, Journal of Materials and Environmental Science, 5, 2572-2583 (2014)

11. K. Belhaj, F. Mansouri, A. Tikent, A. Ouchatbi, M. Boukharta, C.H. Serghini, and A. Elamrani, Revue d'élevage et de médecine vétérinaire des pays tropicaux, 73, 21-26 (2020)

12. F. Pena, J. Perea, A. García, and R. Acero, Meat Science, 75, 543-550 (2007)

13. V. Santos, S. Silva, E. Mena, and J.M.T.d. Azevedo, Meat Science, 77, 654-661 (2007)

14. V. Santos, A. Cabo, P. Raposo, J. Silva, J. Azevedo, and S. Silva, Small Ruminant Research, 130, 136-140 (2015)

15. M. Blasco, M.M. Campo, J. Balado, and C. Sañudo, Journal of the Science of Food and Agriculture, 99, 3335-3342 (2019)

16. B. Yaranoğlu and C. Özbeyaz, Eurasian Journal of Veterinary Sciences, 35, 15-23 (2019)

17. A.G. D’Alessandro, G. Maiorano, M. Ragni, D. Casamassima, G. Marsico, and G. Martemucci, Small Ruminant Research, 114, 97-104 (2013)

18. B. Ekiz, G. Demirel, A. Yilmaz, M. Ozcan, H. Yalcintan, O. Kocak, and A. Altinel, Small Ruminant Research, 114, 26-34 (2013)

19. S. Carrasco, G. Ripoll, A. Sanz, J. Álvarez-Rodríguez, B. Panea, R. Revilla, and M. Joy, Livestock Science, 121, 56-63 (2009)

20. S. Martínez-Cerezo, C. Sañudo, B. Panea, I. Medel, R. Delfa, I. Sierra, J. Beltrán, R. Cepero, and J. Olleta, Meat Science, 69, 325-333 (2005)

21. M. Juárez, A. Horcada, M. Alcalde, M. Valera, O. Polvillo, and A. Molina, Meat Science, 83, 308-313 (2009)

22. G. Mazzone, M. Giammarco, G. Vignola, L. Sardi, and L. Lambertini, Meat science, 86, 474-478 (2010)

23. C. Salifou, A. Youssao, G. Ahounou, P. Tougan, S. Farougou, G. Mensah, and A. Clinquart, Annales de médecine vétérinaire, 157, 27-42 (2013)

24. M. Beriain, P. Bas, A. Purroy, and T. Treacher, Sheep and goat nutrition: Intake, digestion, quality of products and rangelands, 75-86 (2000)

25. K. Budimir, M.F. Trombetta, M. Francioni, M. Toderi, and P. D’Ottavio, Small Ruminant Research, 164, 17 (2018)

26. C. Devine, A. Graafhuis, P. Muir, and B. Chrystall, Meat science, 35, 63-77 (1993)

27. R. Vernon, Lipid metabolism in the adipose tissue of ruminant animals, in Lipid metabolism in ruminant animals, W. William and Christie, Editors. 1981, Elsevier. p. 279-362.

28. B. Ekiz, A. Yilmaz, M. Ozcan, C. Kaptan, H. Hanoglu, I. Erdogan, and H. Yalcintan, Meat science, 82, 6470 (2009)

29. V. Cañeque, C. Pérez, S. Velasco, M. Diaz, S. Lauzurica, I. Álvarez, F.R. De Huidobro, E. Onega, and J. De la Fuente, Meat science, 67, 595-605 (2004)

30. A. Karlsson, Meat science, 31, 423-433 (1992)

31. K. Belhaj, F. Mansouri, A. Tikent, Y. Taaifi, M. Boukharta, H.C. Serghini, and A. Elamrani, The Scientific World Journal, 2021, (2021) 